\title{
Supporting Force Test of Living Water Striders on Water Surface and Mechanical Analysis
}

\author{
Wang Qingcheng $^{1, a}$, Yang Zhuojuan ${ }^{l}$, Shang Guangrui ${ }^{l}$ and Yang Xioadong ${ }^{2, b}$ \\ 1. Jilin Teachers' Institute of Engineering and Technology, Changchun, 130052 \\ 2. Changchun Institute of Technology, Changchun,130021 \\ awqc9341@163.com, ${ }^{b} y 86908051 @ 126 . c o m$
}

\begin{abstract}
Accuracy of designing and producing a micro-force measuring device is $0.1 \mu \mathrm{N}$, through the device, the maximum supporting force of living water striders sample and their legs were measured. The results showed that the maximum supporting force of living water striders is 23.6 times its weight, the maximum supporting force of living water striders greater than the sum of six legs, the reason that living water strider's chest and abdomen touched water surface on process of measuring; Established supporting force model of water strider leg, analyzed the factors associated with supporting force, the key parameters are the water strider leg length and depth of water dimple; Compared the water strider leg's the maximum supporting force of the measurement value and the calculated value according to theoretical model, verified the correctness of the supporting force model.
\end{abstract}

Keywords: water strider; supporting force; measuring device; theoretical model

\section{Introduction}

Water strider is a kind of insect living in ponds, lakes and other water areas, which has 8 legs. In recent years, water strider's superior supporting force have drawn the attention of scientists and engineering technicians and become one of the hot topics researched [13]. Jiang et al [4] deemed that superior supporting force of water strider's legs on water surface is due to its super hydrophobic structure, through experiment they found that the contact angle of water strider's legs is $167^{\circ}$ and the maximum supporting force of water strider's single hind leg is about 15 times of its body weight. Zhang et al [5] conducted chemical modification for gold thread surface, and found that the gold thread with diameter of $1 \mathrm{~mm}$ could float on water surface when its contact angle was $150^{\circ}$. Feng et al [6] conducted theoretical research on the supporting force of super hydrophobic thin rod floating on water surface, and thought that the supporting force of super hydrophobic surface were related to such factors as its contact angle and contact length.

Previous studies limited to the maximum supporting force of water strider's single hind leg, the study of living water strider water supporting force has not yet been reported. This paper designed and produced the measurement device of micro-force, measuring supporting force of living water strider. Through mechanical analysis, established the supporting force mathematical model of water strider on water surface, calculated the maximum supporting force of water strider on water surface according to the model, compared with the experimental measurements, verified the correctness the mathematical model. 


\section{Design of the Measuring Device}

The structure of self-made measuring device is shown in Figure 1, which was mainly used to measure the maximum supporting force of water strider's legs and maximum dimple depth. In this device, analytical balance (GH-252, accuracy of $0.01 \mathrm{mg}$ ) was made by A\&D Co., Ltd; the graduated scale was made of steel, with an accuracy of $0.1 \mathrm{~mm}$; the guide rail was used to ensure the stability in the process of water strider's leg moving downward to water surface; the feed unit was ball screw nut pair, which was driven by AC servo motor controlled by microcomputer, with an accuracy of $0.001 \mathrm{~mm}$. The entire experiment process was recorded by CCD.

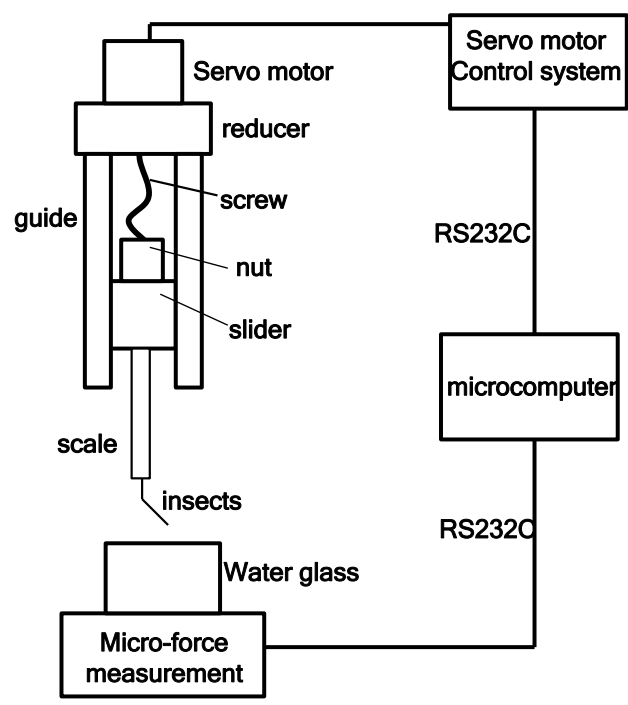

Figure1. Micro Force Measuring Device Structure Diagram

\section{Supporting Force Measuring Experiment}

\subsection{Measuring Experiment of the Living Water Striders}

Dozens of water strider had been captured in South Lake Park in Changchun City, 5 water strider samples were Pick out among them, their weight were measured by analytical balance, the length of the legs were measured by vernier caliper, water strider sample parameters as shown in table 1.

Table1. Water Strider Sample Parameters

\begin{tabular}{ccccc}
\hline Items & $\begin{array}{c}\text { quality } \\
(\mathrm{mg})\end{array}$ & $\begin{array}{c}\text { length of front } \\
\text { legs }(\mathrm{mm})\end{array}$ & $\begin{array}{c}\text { length of middle } \\
\text { legs }(\mathrm{mm})\end{array}$ & $\begin{array}{c}\text { length of hind } \\
\text { legs }(\mathrm{mm})\end{array}$ \\
sample 1 & 20.9 & 6.76 & 15.02 & 19.60 \\
sample 2 & 33.5 & 6.94 & 19.28 & 20.92 \\
sample 3 & 37.2 & 6.97 & 24.10 & 22.48 \\
sample 4 & 39.8 & 7.83 & 23.48 & 22.72 \\
sample 5 & 42.6 & 8.04 & 24.18 & 23.41 \\
average & 34.8 & 7.31 & 21.21 & 21.83 \\
\hline
\end{tabular}


Water strider samples were fixed on the graduated scale of measuring device with double-sided tape, control living water strider uniform downward movement, until water strider legs touching the water, pressed the water dimple on water surface, measured the maximum value of supporting force, measurement experimental were shown in Figure 2(a). The maximum supporting force of 5 water strider sample are shown in Table 2, the maximum supporting force of 5 water strider sample is 23.6 times its own weight.

Table 2. Supporting Force of Living Water Strider

\begin{tabular}{llllll}
\hline Items & sample 1 & sample 2 & sample 3 & sample 4 & sample 5 \\
Body weight $(\mu \mathrm{N})$ & 204.8 & 328.3 & 364.6 & 390.1 & 417.5 \\
The maximum supporting force $(\mu \mathrm{N})$ & 4502.1 & 7736.1 & 8101.7 & 8377.0 & 8736.7 \\
Coefficient of supporting force & 22.0 & 23.6 & 22.2 & 21.5 & 20.9 \\
\hline
\end{tabular}

\subsection{Measuring Experiment of Single Legs of Water Striders}

Cut the legs living water striders sample, which were fixed on the $0.5 \mathrm{~mm}$ diameter iron wire with double-sided tape, the iron wire is fixed on the end of graduated scale of measuring device with double-sided tape, the angle of iron wire and horizontal side of graduated scale end is $45^{\circ}$. Controlling water strider leg moving downwards, when the water strider leg in contact with water surface, adjusting focal length of CCD camera, until the image is clear, Controlling water strider leg press to water surface in $1 \mathrm{~mm} / \mathrm{min}$ speed, the water dimple pressed by water strider leg were shown in Figure 2 (b) (c) (d).the maximum supporting force of water strider single leg and the maximum depth of water dimple were shown in Table 3.

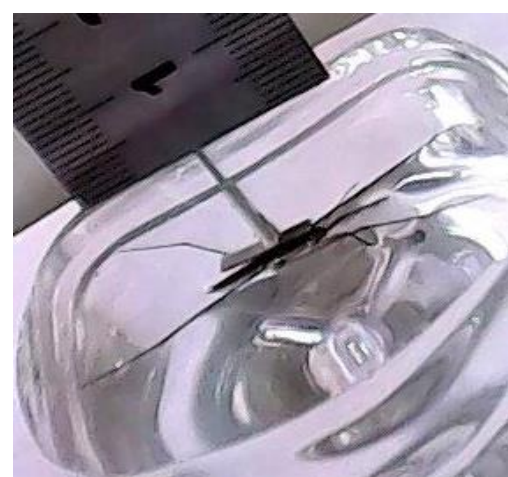

(a) Supporting force measurement test of living water strider

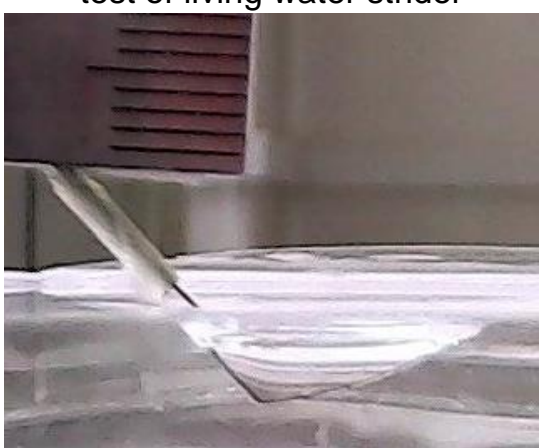

(c) Main view of the water dimple

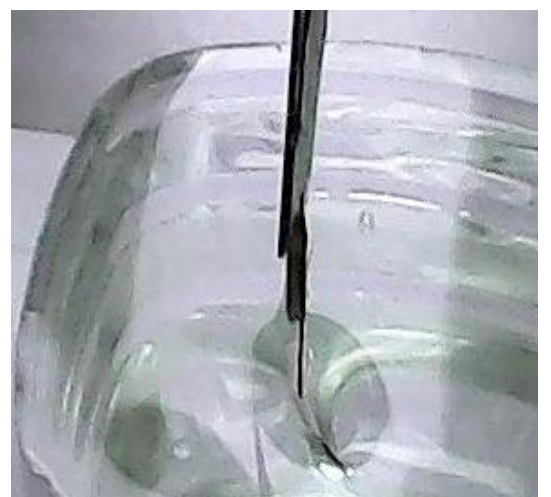

(b) Top view of the water dimple

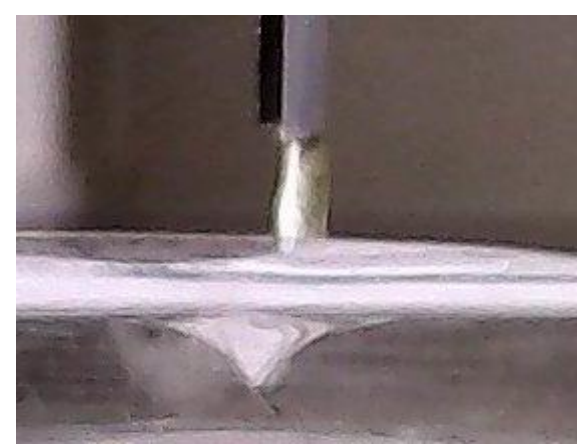

(d) Left view of the water dimple

\section{Figure2. Supporting Force Measurement Test of Living Water Strider and its Legs}


Table 3. The Maximum Supporting Force of Water Strider Leg and the Maximum Depth of Water Dimple

\begin{tabular}{ccrcrcr}
\hline Items & \multicolumn{2}{c}{ front legs } & \multicolumn{2}{c}{ middle leg } & \multicolumn{2}{c}{ hind legs } \\
& $\mathrm{h}(\mathrm{mm})$ & $\mathrm{F}(\mu \mathrm{N})$ & $\mathrm{h}(\mathrm{mm})$ & $\mathrm{F}(\mu \mathrm{N})$ & $\mathrm{h}(\mathrm{mm})$ & $\mathrm{F}(\mu \mathrm{N})$ \\
sample 1 & 2.3 & 342.3 & 3.2 & 1458.6 & 3.7 & 2536.8 \\
sample 2 & 2.3 & 341.2 & 3.3 & 1982.4 & 3.7 & 2658.2 \\
sample 3 & 2.4 & 386.5 & 3.4 & 2650.9 & 3.8 & 2979.4 \\
sample 4 & 2.6 & 500.9 & 3.3 & 2412.6 & 3.8 & 3056.4 \\
sample 5 & 2.7 & 568.2 & 3.4 & 2586.3 & 3.8 & 3124.7 \\
average & 2.5 & 427.8 & 3.3 & 2218.2 & 3.8 & 2871.1 \\
\hline
\end{tabular}

\section{Supporting Force Model and Mechanical Analysis of Water Strider Leg}

\subsection{Supporting Force Model of Water Strider Leg}

When water strider stays on water surface calmly, each leg will cause the dimple. Assuming that water strider's leg is cylindrical, the forces on its cross-section are as shown in Figure 3.

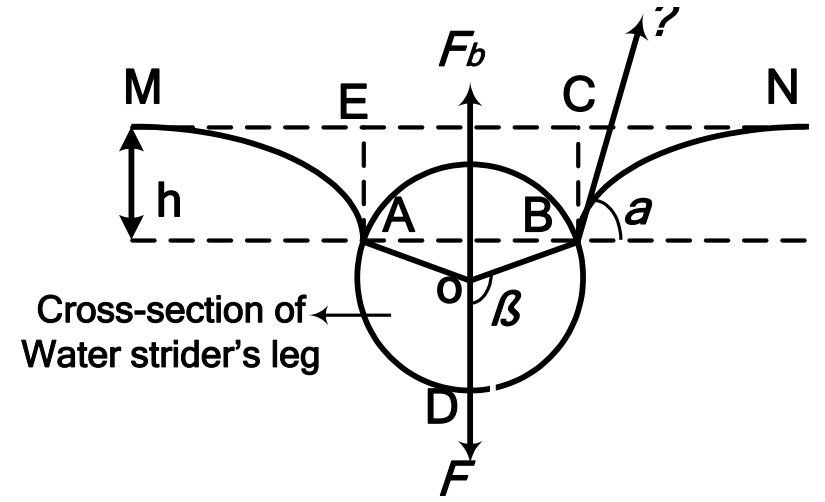

\section{Figure 3. Supporting Force Model of Water Strider's}

Leg

In Figure.3, the dashed line MN represents the horizontal plane; A and B are the contact points between water strider's leg and water surface. Water strider's legs were subject to three forces on water surface, namely pressure F (including body weight supported by leg and force of gravity of leg), surface tension $\gamma$ and buoyancy force $F_{b}$. The buoyancy force is vertically upward, which can be obtained by integrating the hydrostatic pressure over the water strider's legs in contact with water [7-8], and is equal to water displacement of rectangle ABCE drawn by dashed lines in Figure.3. Since the diameter of water strider's leg is very small and approximately equal to the length of line segment $\mathrm{AB}$, the expression of buoyancy force $F_{b}$ is

$$
F_{b}=2 \rho g h L R \sin (\pi-\beta)
$$

In Eq.1, $\rho$ represents water density, g represents gravitational acceleration, $\mathrm{h}$ represents dimple depth, D represents the diameter of water strider's leg, L represents the length of water strider's leg, $\beta$ represents a half central angle of wetted part of the water strider 
legs. The surface tension is in the tangential direction of Point B on liquid-gas interface, and the expression of its vertical component is

$$
F_{s}=2 L \gamma \sin \alpha
$$

In Eq.2, $\gamma$ represents surface tension constant, $\alpha$ represents horizontal angle of tangent of Point B on liquid-gas interface. The vertical component of surface tension was obtained by integrating the curvature pressure over the water strider's legs in contact with water [7-8], which is equal to the sum of water displacement of AME area and water displacement of BCN area in Figure3.

Since the both sides of dimple caused by water strider's leg are symmetrical, the horizontal components of surface tension cancel out each other. In vertical direction, water strider's leg is subject to the pressure, buoyancy force and vertical component of surface tension; the upward force and the downward force are a pair of balanced force. The supporting force (F) of water strider's leg on water surface is equal to the sum of buoyancy force and vertical component of surface tension, and its expression is

$$
F=F_{s}+F_{b}=2 L \gamma \sin \alpha+\rho g D h L
$$

Seen from Eq.3, the supporting force of water strider's leg is related to such factors as $\mathrm{L}, \mathrm{h}, \alpha, \mathrm{D}, \gamma, \rho, \mathrm{g} . \rho, \mathrm{g}$ and $\gamma$ are parameters related to the living environment of the water strider, $\mathrm{L}$ and $\mathrm{D}$ are parameters related to water strider's leg, $\mathrm{h}$ and $\alpha$ is parameters related to dimple. The supporting force of water strider on water surface is composed of buoyancy force and vertical component of surface tension, because diameter of water strider's leg is in the grade of micron, the buoyancy force is only about $1 / 40$ of surface tension [9], which is negligible, that is

$$
F=2 L \gamma \sin \alpha
$$

Water strider leg is flexible, which were bent when it pressed water dimple, each point of water strider leg correspond to the different depth of the water dimple, so $\alpha$ value are also different. According to the existing research literature [10], the relational expression of $\alpha$ and $h$ is

$$
h=\sqrt{\frac{2 \gamma}{\rho g}(1-\cos \alpha)}
$$

The supporting force of each point of water strider leg change with $\alpha$ value, applying element method for integral equations (5), supporting force of water strider leg is

$$
F=\int_{0}^{\alpha} 2 L \gamma \sin \alpha=2 L \gamma(1-\cos \alpha)
$$

Comprehensive analysis expressions (5) and (6) will get expression (7).

$$
F=\rho g L h^{2}
$$

Seen from equation (7), two key parameters affected supporting force of water strider leg is the length of water strider leg (L) and the depth of water dimple (h).

\subsection{Mechanical Analysis of Water Strider Leg}

The water strider leg length (L) in table 1 and the depth of the water dimple in Table 3 were taken into in equation (7), the maximum supporting force of 5 water strider models are calculated, as shown in Table 4. 


\section{Table 4. The Maximum Supporting Force of 5 Water Strider Models}

\begin{tabular}{cccc}
\hline type & front legs & Middle legs & hind legs \\
sample 1 & 350.5 & 1507.3 & 2629.6 \\
sample 2 & 359.8 & 2057.6 & 2806.7 \\
sample 3 & 393.4 & 2730.2 & 3181.2 \\
sample 4 & 518.7 & 2505.8 & 3215.2 \\
sample 5 & 574.4 & 2739.3 & 3312.8 \\
average & 439.4 & 2308.1 & 3029.1 \\
\hline
\end{tabular}

According to Table 3 and Table 4, comparative analysis of errors between measured values and calculated values of supporting force was conducted, as is shown in Figure 4. The error value and the ratio of the error value of supporting forces are shown in Table4. Supporting force error rate of measured values and calculation value of front legs of water strider is less than $5.1 \%$, error rate of middle legs is less than $5.6 \%$, error rate of hind legs is less than 6.3\%. In Figure 4, Abscissa represents leg of 5 water strider samples, point 1-5 represents front legs, point 6-10 represents middle leg, point 11 to 15 represents hind legs.

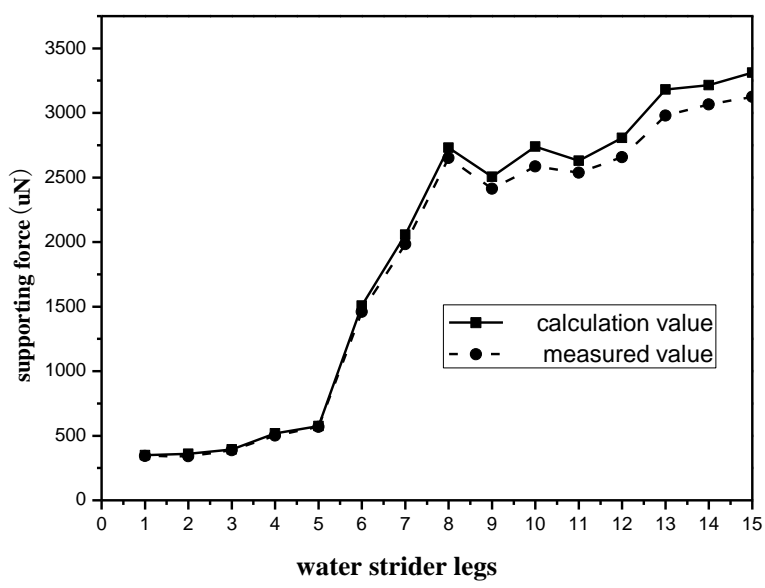

Figure 4. Error Analysis Calculated Values and Measured Values

The measured value is less than the calculated value of supporting forces of the water strider model, which has two reasons.

(1) When supporting forces of the water strider model was measuring, the actual the maximum depth of the dimple is possible smaller than the theoretical calculation.

(2) It is difficult to maintain a state of equilibrium for the water strider model, the process of which the sand was add to the model, because transient partial load, The model has not yet reached maximum value, water surface was pierced by its legs.

\section{Conclusion}

(1) The self-made measuring device was used in the experiment to measure the maximum dimple depth and the maximum supporting force of water strider leg on water surface, its precision is $0.1 \mu \mathrm{N}$, the minimum linear feed speed is $1 \mathrm{~mm} / \mathrm{min}$.

(2) Test measured that the maximum supporting force of water strider leg on water surface is $3124.7 \mu \mathrm{N}$, the maximum supporting force of living water strider sample is 23.6 times its own weight, which is more than the sum of 6 legs of the water strider, the reason 
is that chest, abdomen of living water strider touching surface, increasing the contact area with water surface, which increased supporting force of living water strider.

(3) This paper established supporting force model of water strider flexible legs, which indicates that the key parameters affecting supporting force of water strider legs is leg length of water strider (L) and the depth of water dimple (h). Analyzed the reason that measured values of supporting force of water strider legs is less than calculated value, verified the validity of the theoretical model.

\section{Acknowledgement}

This work was supported by National Natural Science Foundation of China (51275055), Jilin Province Science and Technology Development Project (20140101058JC) and Jilin Provincial Department of Education funded project (2013370).

\section{References}

[1] M. Dickinson, “Animal locomotion: how to walk on water", Nature, vol. 424, no. 6949, (2003), pp. 621622.

[2] D. L. Hu, B. Chan and J. W. M. Bush, "The hydrodynamics of water strider locomotion", Nature, vol. 424, no. 6949, (2003), pp. 663-666.

[3] P. J. Wei, Y. X. Shen and J. F. Lin, "Characteristics of Water Strider Legs in Hydrodynamic Situations", Langmuir, vol. 25, no. 12, (2009), pp. 7006-7009.

[4] X. F. Gao and J. Lei, "Water-repellent legs of water striders", Nature, vol. 432, (2004), no. 26.

[5] S. Feng, N. Jia and L. Jianlin, "Towards understanding why a super hydrophobic coating is needed by water striders", Adv. Mater, vol. 19, (2007), pp. 2257-2261.

[6] J. L. Liu, X. Q. Feng and G. F. Wang, "Buoyant force and sinking conditions of a hydrophobic thin rod floating on water", Physical Review E, vol. 76, no. 066103, (2007).

[7] D. Vella, D. G. Lee and H. Y. Kim, "The Load Supported by Small Floating Objects", Langmuir vol. 22, (2006), pp. 5979-5981.

[8] P. Q. Min , L. Jia and Z. Qing, "A water strider-like model with large and stable loading capacity fabricated from super hydrophobic copper foils", Applied Materials \& Interfaces, vol. 2, no. 7, (2010), pp. 2026-2030.

[9] W. Q. Cheng and Y. X. Dong, "Modeling and analysis of the supporting force of water strider's legs", Applied Mechanics And Mechanical, (2011), pp. 138-139, 356-361.

[10] W. S. Hui and W. L. Cheng, "Statics analysis on the leg of water strider robot", Journal of Beijing University of Aeronautis and Astronautis, vol. 36, no. 10, (2010), pp. 1176-1179. 
International Journal of Control and Automation Vol. 8, No. 4 (2015) 